\title{
LABORATORIUM VIRTUAL (PhET SIMULATION): PENINGKATAN KEMAMPUAN ANALISIS SISWA PADA MATERI GELOMBANG MEKANIK
}

\author{
Adi Resesi Anto ${ }^{1 *}$, Thoha Firdaus ${ }^{1}$, Widayanti ${ }^{1}$, Arini Rosa Sinensis ${ }^{1}$ \\ ${ }^{1}$ Program Studi Pendidikan Fisika Universitas Nurul Huda \\ *Corresponding author: adiresesianto@gmail.com
}

Article History:

Received: Oktober 04, 2021

Revised: November 10, 2021

Accepted: November 30, 2021

Published: Desember 31, 2021

Keywords: Analytical ability, mechanical wave, PhET simulation

\begin{abstract}
Abstrac: Physic Education and Technology (PhET) is a virtual laboratorybased learning media that was created to facilitate practical activities. This study aims to improve students' analytical skills on the concept of mechanical waves. This type of research is quantitative research. This research was conducted at SMP NU Bumirahayu involving 23 students taken by random sampling. This research was conducted using a Quasy Experiment method in the form of Pre-experimental Design using one class. Data was collected by giving pretest and post-test. The type of question used is a description test. The data analysis technique used the $N$-gain test. The results of the study on the calculation of $N$-gain showed that the average pretest score was 36.61 while the average post-test score was 90.17. Based on the results of the N-gain calculation, it can be seen that learning using virtual laboratory media (PhET Simulation) can improve students' analytical skills. For researchers who will apply learning using virtual laboratory media, they should be able to display simulations with the latest innovations so that the goals are achieved and the final learning outcomes are even better.
\end{abstract}

\begin{abstract}
Abstrak: Physic Education and Technology (PhET) merupakan salah satu media pembelajaran berbasis laboratorium virtual yang dirancang untuk memudahkan siswa dalam mendeskripsikan laboratorium nyata. Tujuan dalam penelitian ini adalah untuk meningkatkan kemampuan analisis siswa pada materi pembelajaran gelombang mekanik. Penelitian ini dilakukan di SMP NU Bumirahayu, dengan sampel 23 siswa. Jenis penelitian ini adalah penelitian kuantitatif dengan metode Quasi Eksperimen berbentuk Pre Experimental Design dengan menggunakan satu kelas. Jenis pengumpulan data dilakukan dengan pemberian soal awal (pretest) dan soal akhir (posttest). Jenis soal yang digunakan tes uraian. Analisis data menggunakan uji $N$-gain. Hasil penelitian pada perhitungan $\mathrm{N}$-gain menunjukkan rata-rata nilai awal (pretest) sebesar 36,61 sedangkan nilai akhir (posttest) sebesar 90,17. Berdasarkan hasil perhitungan nilai $\mathrm{N}$-gain dapat diketahui bahwa pembelajaran menggunakan media laboratorium virtual (PhET Simulation) dapat meningkatkan kemampuan analisis siswa. Bagi peneliti yang akan menerapkan pembelajaran menggunakan media laboratorium virtual sebaiknya dapat menghadirkan simulasi dengan inovasi terbaru agar dapat tercapainya tujuan pembelajaran dengan hasil akhir kegiatan pembelajaran lebih baik.
\end{abstract}

\section{PENDAHULUAN}

Fisika merupakan salah satu bagian dari mata pelajaran Ilmu Pengetahuan Alam (IPA) yang mempelajari suatu peristiwa dan gejala yang terjadi di alam semesta (Hidayah, 2020). Terdapat konsep fisika yang bersifat abstrak, sehingga dalam proses pembelajaran membutuhkan media agar lebih konkret (Rais, Hakim, \& Sulistiawati, 2020).

Peran media sangat membantu dalam kegiatan pembelajaran (Arda, 2020). Media pembelajaran yang efektif dapat menciptakan ketertarikan kepada peserta didik pada materi yang disampaikan (Yunita, Halim, \& Safitri, 2019). 
Seiring berkembangnya dunia teknologi, banyak berkembang jenis media pembelajaran (Sumargo \& Yuanita, 2014). Berbagai jenis media pembelajaran tersebut berupa gambar, video animasi, buku elektronik (ebook), powerpoint, serta laboratorium virtual (Hidayah, 2020). Terbatas dan kurangnya peralatan di laboratorium saat kegiatan praktikum mengakibatkan siswa kurang optimal dalam proses pembelajaran (Abdi, Mustafa, \& Pada, 2021). Hal ini merupakan faktor penghambat kemampuan analisis siswa (Mirdayanti \& Murni, 2017).

Salah satu teknologi yang tepat dan sesuai dengan perkembangan zaman di era millenial saat ini adalah laboratorium virtual (Masita, Donuata, Ete, \& Rusdin, 2020). Laboratorium virtual dapat menggantikan percobaan yang dilakukan pada laboratorium nyata (Irfan Yusuf dan Sri Wahyu Widyaningsih, 2018). Laboratorium virtual merupakan media simulasi interaktif berbasis komputer (Abdjul \& Ntobuo, 2019). Laboratorium virtual dapat digunakan dalam membantu proses pembelajaran praktikum fisika untuk meningkatkan kemampuan analisis siswa dan membantu keterbatasan laboratorium nyata (Hikmah, Saridewi, \& Agung, 2017).

Salah satu jenis laboratorium virtual yang dapat digunakan oleh peserta didik dalam mendukung pembelajaran fisika untuk membantu meningkatkan kemampuan analisis siswa adalah PhET Simulation (Hidayat, Hakim, \& Lia, 2019). Oleh sebab itu, simulasi PhET bermanfaat bagi peserta didik yang membutuhkan suatu media simulasi laboratorium virtual (Dewa, Ursula Jawa Mukin, \& Pandango, 2020).

Berdasarkan observasi yang telah dilakukan oleh peneliti pada instansi Pendidikan sekolah menengah pertama ditemukan bahwa peralatan praktikum yang tersedia sangat terbatas dan kurang lengkap sehingga proses kegiatan praktikum berjalan kurang efektif terutama pada materi pembelajaran gelombang mekanik. Hal ini mengakibatkan siswa kurang aktif dan menurunnya kemampuan analisis siswa dalam materi pembelajaran gelombang mekanik (Iman Sari, Gunawan, Harjono, \& Sahidu, 2017)

Hasil penelitian yang dilakukan oleh Wulandari \& Vebrianto (2017), kegiatan praktikum menggunakan laboratorium virtual memberikan rasa nyaman dan aman kepada peserta didik. Memudahkan peserta didik memahami materi yang disampaikan menggunakan laboratorium virtual. Penelitian yang dilakukan Iman Sari et al., (2017), menunjukkan adanya peningkatan yang signifikan terhadap kemampuan penguasaan materi pembelajaran menggunakan media laboratorium virtual.

Atas dasar inilah peneliti merumuskan masalah terkait upaya meningkatkan kemampuan analisis siswa pada meteri gelombang mekanik. Penelitian ini bertujuan untuk mendeskripsikan pemanfaatan media laboratorium virtual sebagai simulasi secara visual untuk mendeskripsikan percobaan praktikum gelombang mekanik di laboratorium nyata. Diharapkan dari penelitian ini siswa dapat memenuhi indikator ketercapaian kemampuan analisis dengan bantuan laboratorium virtual PhET Simulation.

\section{METODE PENELITIAN}

Pada penelitian ini, jenis penelitian yang peneliti gunakan adalah penelitian kuantitatif dengan metode Quasy Experimental Design dengan desain penelitian One Group Pretest Posttest Design. Bentuk desain penelitian disajikan seperti pada Gambar 1.

$$
\mathrm{O}_{1} \times \mathrm{O}_{2}
$$

Gambar 1. Desain Penelitian 
Keterangan:

$O_{1}$ : Sebelum eksperimen (Pretest)

$\mathrm{X}$ : Perlakuan yang diberikan yaitu pembelajaran menggunakan media laboratorium virtual (PhET Simulation)

$\mathrm{O}_{2}$ : Setelah eksperimen (Posttest).

Instrumen penelitian yang digunakan berupa tes dan angket. Tes digunakan untuk mengukur kemampuan analisis siswa dan angket digunakan untuk mengukur respon siswa. Soal berbentuk tes uraian dan angket berupa angket respon siswa. Teknik analisis data yang digunakan berupa soal pretest dan soal posttest. Pada tes awal belum diberikan perlakuan menggunakan media PhET Simulation dan pada tes akhir diberikan perlakuan menggunakan media PhET Simulation.

Populasi penelitian ini adalah seluruh siswa kelas VIII SMP NU Bumirahayu. Sampel penelitian ini diambil secara cluster random sampling yaitu kelas VIII SMP NU Bumirahayu.

Teknik pengumpulan data menggunakan tes uraian berdasarkan indikator kemampuan analisis materi gelombang mekanik dengan tingkat kesulitan mencakup seluruh perangkat instrumen penelitian tersebut. Terdapat 7 soal pada 2 indikator kemampuan analisis yang digunakan, yakni:

1. Mampu memahami makna dari sebuah teori (soal 1-3).

2. Mampu membuat kesimpulan dari beberapa pertanyaan atau pernyataan (soal 4-7).

Soal pada penelitian ini telah di validasi.

\section{HASIL DAN PEMBAHASAN}

Pengambilan data tentang kemampuan analisis siswa yang proses pembelajarannya tidak menggunakan media PhET Simulation dan menggunakan media PhET Simulation ditetapkan dengan data yang diambil dari nilai tes Pretest dan nilai tes Posttest. Nilai tersebut kemudian dianalisis untuk memperoleh kesimpulan dari hasil penelitian. Hasil nilai tes siswa sebelum dan sesudah diterapkannya media PhET Simulation ditunjukkan pada grafik 1.

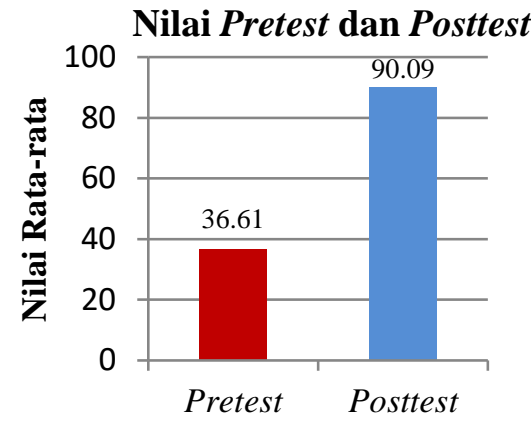

Grafik 1. Nilai tes Kemampuan Analisis Siswa

Berdasarkan grafik 1, terlihat nilai rata-rata posttest mengalami peningkatan yang signifikan dibandingkan nilai ratarata pretest. Hal tersebut menunjukkan adanya peningkatan kemampuan analisis siswa sebelum dan sesudah diterapkannya media laboratorium virtual PhET Simulation.

Perbedaan hasil tes kemampuan analisis siswa yang pembelajarannya belum menggunakan simulasi PhET Simulation dan pembelajaran yang telah menggunakan simulasi PhET Simulation dapat dilihat dari hasil uji $N$-gain kemampuan analisis. Tabel 1 berikut menunjukkan hasil uji $\mathrm{N}$-gain kemampuan analisis siswa.

Tabel 1. Hasil Uji $N$-gain Kemampuan Analisis Siswa

\begin{tabular}{|c|c|c|c|c|}
\hline \multirow{2}{*}{$\begin{array}{c}\text { Indikator } \\
\text { Kemampuan } \\
\text { Analisis }\end{array}$} & \multicolumn{2}{|c|}{$\begin{array}{c}\text { Total Skor } \\
\text { Tes }\end{array}$} & \multirow{2}{*}{$\begin{array}{l}N- \\
\text { gain }\end{array}$} & \multirow{2}{*}{ Kriteria } \\
\hline & $\begin{array}{l}\text { Pre } \\
\text { test }\end{array}$ & $\begin{array}{c}\text { Post } \\
\text { test }\end{array}$ & & \\
\hline $\begin{array}{l}\text { Mampu } \\
\text { memahami } \\
\text { makna dari } \\
\text { sebuah teori }\end{array}$ & 1,74 & 87,8 & 1,01 & Tinggi \\
\hline $\begin{array}{l}\text { Mampu } \\
\text { membuat } \\
\text { kesimpulan dari } \\
\text { beberapa } \\
\text { pertanyaan atau } \\
\text { pernyataan }\end{array}$ & 80,9 & 92,9 & 0,43 & Sedang \\
\hline Nilai $N$-gain & & $\mathbf{0 , 8 3}$ & & Tinggi \\
\hline
\end{tabular}


Perbedaan yang terjadi pada hasil uji $\mathrm{N}$-Gain tabel 1 menunjukkan bahwa nilai posttest pada indikator kemampuan analisis terjadi peningkatan yang cukup signifikan dibandingkan dengan nilai pretest. Dapat disimpulkan bahwa penerapan pembelajaran gelombang mekanik menggunakan media PhET Simulation mengalami peningkatan kemampuan analisis. Hal ini juga dapat ditinjau berdasarkan hasil pengerjaan soal yang sama pada gambar 2 dan 3 berikut.

Soal: Jika sebuah gelombang panjangnya $2,5 \mathrm{~m}$ dan berfrekuensi $40 \mathrm{~Hz}$, maka gelombang tersebut merambat dengan kecepatan?

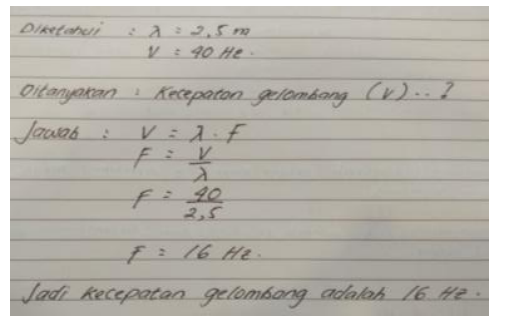

Gambar 2. Jawaban pretest siswa

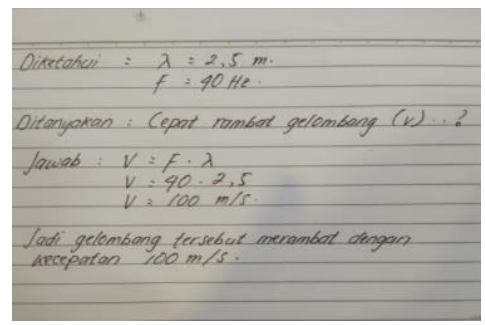

Gambar 3. Jawaban posttest siswa

Berdasarkan hasil pengerjaan soal yang sama pada gambar 2 dan 3 (soal pretest dan soal posttest) dapat disimpulkan bahwa pada soal pretest siswa belum mampu menganalisis jawaban dengan benar yang berarti kemampuan analisis siswa masih kurang. Namun, setelah diberikan perlakuan pembelajaran menggunakan simulasi PhET Simulation siswa menjawab dengan benar. Hal ini dikarenakan siswa mengalami peningkatan kemampuan analisis menggunakan simulasi PhET Simulation yang mudah dipahami oleh siswa.

Hal ini juga dapat ditinjau berdasarkan hasil nilai $N$-Gain dengan kategori tinggi. Hal tersebut dapat dilihat pada tabel 1 nilai $N$-gain 0,83 dengan kategori tinggi.

Hal ini di dukung penelitian yang dilakukan oleh Yunita et al., (2019) hasil analisis data menunjukkan bahwa persentase rata- rata $N$-gain penguasaan konsep mahasiswa adalah $60 \%$ dengan kategori sedang. Dengan hasil yang diperoleh menunjukkan bahwa pembelajaran dengan simulasi PhET dapat meningkatkan penguasaan konsep.

\section{KESIMPULAN DAN SARAN}

Kesimpulan dari hasil penelitian ini bahwa media pembelajaran laboratorium virtual PhET Simulation berpengaruh secara signifikan terhadap kemampuan analisis siswa. Hal ini dapat dilihat dari masing-masing nilai pretest dan posttest tiap indikator kemampuan analisis. Hal ini terbukti dari hasil nilai $N$ gain 0,83 dengan kategori tinggi.

Saran peneliti selanjutnya dalam penerapan media laboratorium virtual dapat mengembangkan berbagai jenis simulasi yang lain sehingga dapat menghadirkan kegiatan belajar mengajar di kelas dengan efektif dan inovasi baru, serta tujuan dan hasil akhir dari kegiatan pembelajaran dapat tercapai dengan baik.

\section{DAFTAR PUSTAKA}

Abdi, M. U., Mustafa, M., \& Pada, A. U. T. (2021). Penerapan Pendekatan STEM Berbasis Simulasi PhET Untuk Meningkatkan Pemahaman Konsep Fisika Peserta Didik. Jurnal IPA \& Pembelajaran IPA, 5(3), 209218.

https://doi.org/10.24815/jipi.v5i3.21 774

Abdjul, T., \& Ntobuo, E. (2019). Penerapan Media Pembelajaran Virtual Laboratory Berbasis PhET terhadap Hasil Belajar Siswa pada Materi Gelombang. Jurnal Pendidikan Fisika Tadulako Online (JPFT), 7(3), 26-31. 
Arda, A. (2020). Penerapan Media Simulasi PhET Terhadap Hasil Belajar Konsep Dasar IPA Mahasiswa Tadris IPA Iain Palu. Guru Tua: Jurnal Pendidikan Dan Pembelajaran, 3(1), 29-34. https://doi.org/10.31970/gurutua.v3i 1.43

Dewa, E., Ursula Jawa Mukin, M., \& Pandango, O. (2020). Pengaruh Pembelajaran Daring Berbantuan Laboratorium Virtual Terhadap Minat dan Hasil Belajar Kognitif Fisika. Jurnal Riset Teknologi Dan Inovasi Pendidikan (JARTIKA), 3(2), 351-359.

https://doi.org/10.36765/jartika.v3i2. 269

Hidayah, U. M. (2020). Hubungan Penggunaan Lembar Kerja Siswa (LKS) dengan Hasil Belajar Mata Pelajaran Ilmu Pengetahuan Alam Kelas V di MI Tarbiyatul Banin Banat Alasdowo Dukuhseti Pati Tahun Ajaran 2019/2020 (Vol. 15). STAIN Kudus.

Hidayat, R., Hakim, L., \& Lia, L. (2019). Pengaruh Model Guided Discovery Learning Berbantuan Media Simulasi PhET Terhadap Pemahaman Konsep Fisika Siswa. Berkala Ilmiah Pendidikan Fisika, 7(2), 97-104. https://doi.org/10.20527/bipf.v7i2.59 00

Hikmah, N., Saridewi, N., \& Agung, S. (2017). Penerapan Laboratorium Virtual Untuk Meningkatkan Pemahaman Konsep Siswa. Jurnal Kimia Dan Pendidikan, 2(2), 186195.

Iman Sari, P., Gunawan, Harjono, A., \& Sahidu, H. (2017). Pengaruh Pembelajaran Discovery Berbantuan Media Laboratorium Virtual Terhadap Penguasaan Konsep Dan Kemampuan Pemecahan Masalah Fisika Peserta Didik. In A. Setiawan, W. Widodo, \& Gunawan (Eds.), Laboratorium Virtual Dan
Aplikasinya Dalam Pembelajaran Fisika (Pertama, pp. 159-174). Retrieved from http://eprints.unram.ac.id/id/eprint/4 626

Masita, S. I., Donuata, P. B., Ete, A. A., \& Rusdin, M. E. (2020). Penggunaan PhET Simulation Dalam Meningkatan Pemahaman Konsep Fisika Peserta Didik. Jurnal Penelitian Pendidikan Fisika, 5(2), 136-141.

Mirdayanti, R., \& Murni. (2017). Kajian Penggunaan Laboratorium Virtual Berbasis Simulasi Sebagai Upaya Mengatasi Ketidak-Sediaan Laboratorium. Jurnal Visipena, 8(2), 323-330.

Rais, A. A., Hakim, L., \& Sulistiawati, S. (2020). Pemahaman Konsep Siswa melalui Model Inkuiri Terbimbing Berbantuan Simulasi PhET. Physics Education Research Journal, 2(1), 18.

https://doi.org/10.21580/perj.2020.2. 1.5074

Sumargo, E., \& Yuanita, L. (2014). Penerapan Media Laboratorium Virtual (PhET) Pada Materi Laju Reaksi Dengan Model Pengajaran Langsung. Unesa Journal of Chemical Education, 3(1), 119-133.

Wulandari, N., \& Vebrianto, R. (2017). Studi Literatur Pembelajaran Kimia Berbasis Masalah Ditinjau Dari Kemampuan Menggunakan Laboratorium Virtual. 18-19.

Yunita, Halim, A., \& Safitri, R. (2019). Meningkatkan Penguasaan Konsep Mahasiswa Dengan Simulasi Physics Eduaction and Technology (PhET). Jurnal Pendidikan Sains Indonesia, 07(01), $16-22$. https://doi.org/10.24815/jpsi.v7i1.13 492 